\title{
Digestive physiology, resting metabolism and methane production of captive Indian crested porcupine (Hystrix indica)
}

\author{
K.B. Hagen ${ }^{1}$, S. Hammer ${ }^{2}$, S. Frei ${ }^{1}$, S. Ortmann ${ }^{3}$, R. Głogowski ${ }^{4}$, M. Kreuzer ${ }^{5}$ and M. Clauss ${ }^{1,6}$ \\ 1 University of Zurich, Vetsuisse Faculty, Clinic for Zoo Animals, Exotic Pets and Wildlife, \\ Winterthurerstr. 260, 158057 Zurich, Switzerland \\ ${ }^{2}$ Naturschutz-Tierpark Görlitz, Zittauerstrasse 43, D-02826 Görlitz, Germany \\ ${ }^{3}$ Leibniz Instiute for Zoo and Wildlife Research (IZW) Berlin, Alfred-Kowalke Str. 17, 10315 Berlin, Germany \\ ${ }^{4}$ Warsaw University of Life Sciences (WULS) - SGGW, Faculty of Animal Sciences, Department of Animal Breeding, \\ Ciszewskiego 8, 02-786 Warsaw, Poland \\ ${ }^{5}$ ETH Zurich, Institute of Agricultural Sciences, Universitätsstr. 2, 8092 Zurich, Switzerland
}

KEY WORDS: Hystricomorpha, Rodentia, mean retention time, digestibility, basal metabolic rate, colonic separation mechanism

Received: 29 November 2018

Revised: 9 January 2019

Accepted: 18 February 2019

${ }^{6}$ Corresponding author:

e-mail: mclauss@vetclinics.uzh.ch

\begin{abstract}
Limited physiological measurements exist for the digestive physiology of porcupines. We measured $\mathrm{CH}_{4}$ emission in three captive Indian crested porcupines (Hystrix indica; $16.1 \pm 2.7 \mathrm{~kg}$ ) fed a diet of pelleted lucerne, and measured feed intake, digestibility, and digesta mean retention time (MRT) of a solute and three particle markers (<2, 10 and $20 \mathrm{~mm}$ ). Marker excretion patterns suggested secondary peaks indicative of caecotrophy, with MRTs of $26.4 \mathrm{~h}$ for the solute and $31.5,26.8$ and $26.2 \mathrm{~h}$ for the three particle markers, respectively. At a dry matter intake of $58 \pm 10 \mathrm{~g} / \mathrm{kg}$ body mass ${ }^{0.75} /$ day, porcupines digested 49 and $35 \%$ organic matter and neutral detergent fibre, respectively, which is in the lower range of that expected for horses on a similar diet. The respiratory quotient $\left(\mathrm{CO}_{2} / \mathrm{O}_{2}\right)$ was 0.91 , the resting metabolic rate $274 \mathrm{~kJ} / \mathrm{kg}$ body mass ${ }^{0.75} / \mathrm{day}$, and $\mathrm{CH}_{4}$ emissions averaged at $8.16 \mathrm{I} /$ day and $17.9 \mathrm{l} / \mathrm{kg}$ dry matter intake. Accordingly, $\mathrm{CH}_{4}$ yield was so high that it resembled that of a hypothetical ruminant of this body mass. The results are in accord with general understanding of hystricomorph rodent digestive physiology, and support recent findings that $\mathrm{CH}_{4}$ production may be more prominent in rodents than previously thought.
\end{abstract}

\section{Introduction}

The appearance of porcupines has always fascinated biologists and laypersons alike, but their digestive physiology has received comparatively little attention. Porcupines - the Hystricidae - have provided the name for a large group of rodents called the Hystricomorpha. This group is characterised by a simple stomach and a comparatively voluminous caecum (van Jaarsveld and Knight-Eloff, 1984; Vispo and Hume, 1995; Figure 1A). In addition, the proximal colon (large intestine) has a spe- cific anatomical structure, namely two longitudinal bands that form a 'furrow' or 'groove' (Gorgas, 1967; Figure 1B), that collects microbes from the colonic digesta and transport them backwards into the caecum. Typically, the contents of the caecum are, at some stage during the day, expelled and reingested by such species in the process called 'coprophagy' or 'caecotrophy' (Hirakawa, 2001). Although these two terms are often used interchangeably, 'caecotrophy' is the more accurate term, as it describes the ingestion of a special kind of faeces (the 'caecotrophs'), whereas 'coprophagy' could denote the 
ingestion of any kind of faeces, also of the so-called 'hard faeces'. Therefore, the term 'caecotrophy' will be used from here on.

Caecotrophy is well-documented in a large number of hystricomorph rodent species (Hirakawa, 2001). Nevertheless, various authors have stated that porcupines do not practice caecotrophy (Johnson and McBee, 1967; van Jaarsveld and Knight-Eloff, 1984; Björnhag, 1987; Vispo and Hume, 1995). This assumption is so firmly anchored in the concept of porcupine function that even when in a study of Felicetti et al. (2000) on digesta passage, markers showed secondary excretion peaks typical for caecotrophic species (Clauss et al., 2007), this was not interpreted as a reflection of caecotrophy. In this context, it should be noted that other hystricomorph rodents (capybara, Hirakawa, 2001; nutria, Hagen et al., 2019), for which today caecotrophy is generally accepted as a component of their digestive strategy, have historically been also explicitly described as non-coprophagic. Given this historical development in other hystricomorph species, and the presence of a colonic groove in Hystricidae (old-world

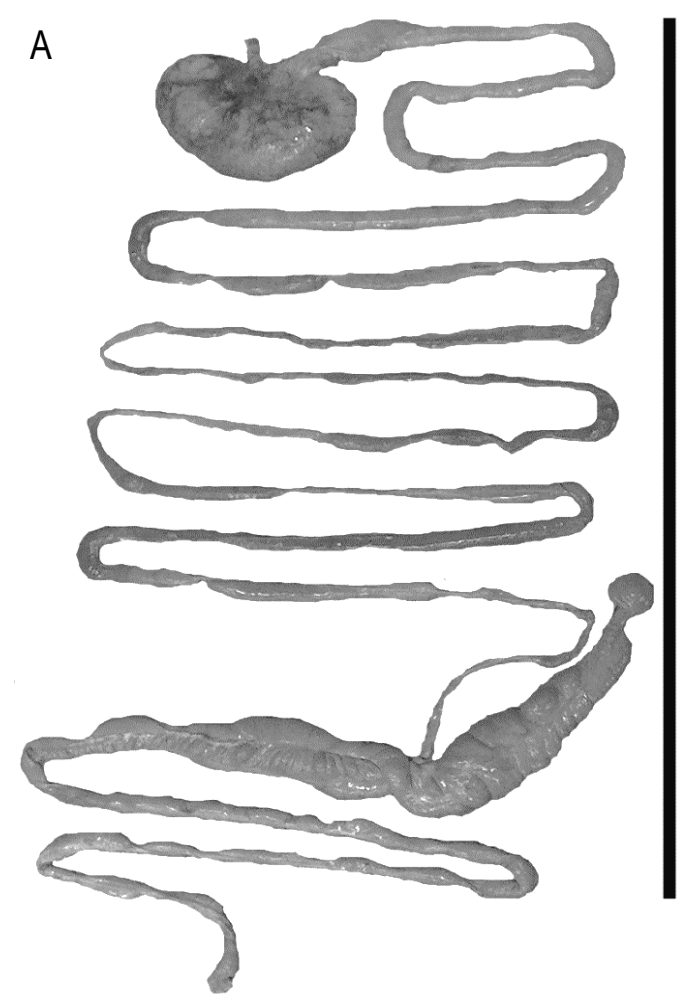

B

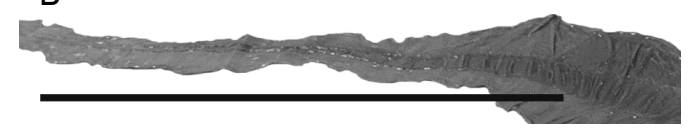

Figure 1. (A) Gastrointestinal tract of an Indian crested porcupine (Hystrix indica; scale bar $=100 \mathrm{~cm}$ ), with $(\mathrm{B})$ a view on the internal side of the opened proximal colon below with the colonic groove (scale bar $=50 \mathrm{~cm}$ ) porcupines, see also Figure 1B) and Erethizontidae (new-world porcupines) (Gorgas, 1967) that is related to a colonic separation mechanism and coprophagy in other species, we hypothesize that porcupines practice caecotrophy as well.

Summarizing the natural diets of porcupines ( $H y s^{-}$ tricidae and Erethizontidae), most representatives of these families are considered herbivores that consume a variety of browse, grass, bulbs, roots or fruits (Mori et al., 2017). Microbial fermentation takes place in the porcupine caecum and proximal colon (Johnson and McBee, 1967; van Jaarsveld and Knight-Eloff, 1984), and digesta passage ranges between 23 and 96 h (van Jaarsveld, 1983; Riccardi and Bruno, 1996; Felicetti et al., 2000). Hystricomorph rodents are thought to have, with their colonic groove, a so-called 'mucus trap' colonic separation mechanism which is characterised by a more or less simultaneous passage of fluid and particles through the digestive tract (Pei et al., 2001). However, the only study that employed both types of markers together in a porcupine species so far found a distinctively longer retention of the fluid marker (Felicetti et al., 2000). Another characteristic of porcupines is that they achieve comparatively high fibre digestibility (van Jaarsveld, 1983; Felicetti et al., 2000).

Irrespective of caecotrophy, an unavoidable side effect of microbial fibre fermentation is the production of methane $\left(\mathrm{CH}_{4}\right)$. It has also been detected in porcupine faeces (Hackstein and van Alen, 1996) and hindgut contents (van Jaarsveld and KnightEloff, 1984) incubated in vitro. Although in the former study, porcupine (Coendou prehensilis) faeces had yielded the highest amounts of $\mathrm{CH}_{4}$ of any rodent species (and, e.g., higher than horse faeces), the latter study suggested a comparatively low absolute daily $\mathrm{CH}_{4}$ emission of only 0.11 in Hystrix africaeaustralis.

In the present study, we measured apparent digestibility of nutrients and energy, digesta passage and $\mathrm{CH}_{4}$ production in three captive Indian crested porcupines (Hystrix indica) fed a high fibre diet, in order to further characterize the digestive physiology of porcupines.

\section{Material and methods}

Three adult captive Indian crested porcupines [Hystrix indica; one male and two females; body mass (BM): $16.1 \pm 2.7 \mathrm{~kg}$ ] were available for the present study. Animal experiments were in accordance with the Swiss Cantonal Animal Care and Use Committee Zurich, animal experiment licence no. 142/2011. Animals were weighed at the beginning and the 
Table 1. Nutrient composition of the lucerne pellets used in the present study, g/kg dry matter

\begin{tabular}{ll}
\hline Indices & Content \\
\hline Organic matter & 876 \\
Crude protein & 155 \\
Total ash & 124 \\
Crude fibre & 308 \\
Neutral detergent fibre & 492 \\
Acid detergent fibre & 360 \\
Gross energy, MJ/kg & 18.0 \\
\hline
\end{tabular}

end of the experiment, and no change in BM was detected. Animals were kept in three separate roofed outdoor enclosures (ranging in size from 19 to $40 \mathrm{~m}^{2}$ ) with a concrete floor and a shelter $\left(1.1 \mathrm{~m}^{2}\right)$. Heavy ceramic dishes were provisioned with water and feed for ad libitum consumption. The animals had visual, olfactory, acoustic and tactile contact amongst each other via meshed enclosure walls. Straw served as bedding material in the shelter, after it had been verified (by observation and sporadic weighing during the adaptation period) that the animals did not consume straw. The animals had been familiarised with the enclosures and with a diet of $4 \mathrm{~mm}$ pelleted lucerne (Medicago sativa, Table 1) for 2 weeks prior to the experiment.

The amount of feed offered and leftovers as well as the faeces produced were quantified on a daily basis by weighing. Samples were taken for the analyses specified below. Digestibility was calculated from the amounts of feed ingested and faeces excreted across five consecutive days. Samples of feed and faeces were subjected to standard nutrient analyses (AOAC International, 2016) including dry matter (DM) and total ash (no. 942.05), crude protein (no. 977.02), neutral detergent fibre (NDF; no. 2002.04), acid detergent fibre (ADF; no. 973.18), and crude fibre (no. 930.10; only feed). Gross energy (GE) was determined by bomb calorimetry (IKA-Calorimeter C4000, Ika, Stauffen, Germany). All fibre values were corrected for ash content. There is a consensus that the detergent fibre system is better suited to characterise fibre content of plant material than crude fibre and that for an understanding of dietary plant fibre, crude fibre values are unsuitable because of the undefined nature of the components retained in this analysis. However, the close association of crude fibre levels with digestibility in herbivores makes this measure suitable for a comparison of the digestive efficiency of different animal species or groups. We used the dietary crude fibre value strictly in this latter context and did not imply that it is of value for nutritional evaluation. All analyses were performed in duplicate.
Organic matter $(\mathrm{OM})$ was calculated as DM minus total ash. The apparent digestibility $(\mathrm{aD})$ of $\mathrm{DM}$ and nutrients was calculated as the percentage of the respective intake not eliminated via faeces.

Cobalt (Co)-EDTA was used as solute marker for the fluid digesta component. Hay particles of 1-2 mm length mordanted with chromium $(\mathrm{Cr})$, of $10 \mathrm{~mm}$ with cerium (Ce), and of $20 \mathrm{~mm}$ with lanthanum (La) were used as particle markers (Schwarm et al., 2009). Markers were offered, after dissolving the Co-EDTA, as one dosage in a batch of feed ( $0.4 \mathrm{~g}$ Co-EDTA and $3 \mathrm{~g}$ of each mordanted fibre per animal). It should be noted that markers were masticated during oral processing by the animals, and particle marker sizes therefore represent the material as offered but not as processed in the gastrointestinal tract. Prior to marker feeding, faecal samples were taken for assessing the background levels of the markers. After marker application, faeces were collected at $4,8,12,16,20$, $24,28,32,36,40,44,48,54,60,66,76,82,90,97$, 103 and $114 \mathrm{~h}$ after marker application.

After drying, faecal samples were analysed for marker concentrations by microwave wet ashing followed by analysis of $\mathrm{Co}, \mathrm{Cr}$, $\mathrm{Ce}$ and $\mathrm{La}$ with an inductively coupled plasma optical emission spectrometer (model Optima 8000, Perkin Elmer, Rodgau, Germany). Marker excretion patterns were visualized with plots depicting faecal marker concentrations over time (Clauss et al., 2007) expressing concentrations in $\%$ of the peak concentration to compensate for differences in absolute concentrations achieved for the different markers. The mean retention time (MRT) in the whole digestive tract was calculated according to Thielemans et al. (1978) as:

$$
\mathrm{RT}=\frac{\sum \mathrm{t}_{\mathrm{i}} * \mathrm{C}_{\mathrm{i}} * \mathrm{dt}_{\mathrm{i}}}{\sum \mathrm{C}_{\mathrm{i}} * \mathrm{dt}_{\mathrm{i}}}
$$

where: $\mathrm{C}_{i}-$ marker concentration in the faecal samples from the interval represented by time $t_{i}(h$ after marker administration, using the midpoint of the sampling interval) and $\mathrm{dt}_{\mathrm{i}}$ - interval (h) of the respective sample:

$$
d t_{i}=\frac{\left(t_{i+1}-t_{i}\right)+\left(t_{i}-t_{i-1}\right)}{2} .
$$

The markers were assumed to have been excreted completely once the faecal marker concentrations were similar to the background levels determined in pre-dose faecal samples. The relative DM intake (DMI) was expressed both on the mammalian average basis of $\mathrm{kg} \mathrm{BM}^{0.75}$ and the more appropriate basis for small herbivores of $\mathrm{kg} \mathrm{BM}^{0.67}$. The total DM gut fill was calculated according to Holleman and White (1989) using DMI, MRT ${ }_{\text {particle }}$ and aD DM. 
After the collection period, the animals were guided into transport boxes and transferred for $23 \mathrm{~h}$ to boxes serving as respiration chambers and placed in a building. These boxes had a plexiglas window that was used to assess the behaviour of the animals using a red light. Feed and water in amounts sufficient for $23 \mathrm{~h}$ were provided in the chambers. The edges of the wooden boxes were sealed with duct tape or silicon. The chambers had been fitted with air inlets of a diameter of $4 \mathrm{~cm}$ at the bottom and air outlets on the top to ensure a constant airflow generated by a pump (Flowkit 100 and Turbofox, Sable Systems, Las Vegas, NV, USA; average flow $55 \pm 31$ / $\mathrm{min})$. These holes were protected against gnawing by meshed metal sheets of $2 \mathrm{~mm}$ thickness. Out-flowing air was ducted via flexible hoses to a gas multiplexer, which allowed the simultaneous measurement of up to two individuals and baseline values from ambient air, at intervals of $90 \mathrm{~s}$ per chamber. Gas concentrations were measured by $\mathrm{O}_{2}$ and $\mathrm{CO}_{2}$ analysers (Turbofox, Sable Systems, Las Vegas, NV, USA) and by a $\mathrm{CH}_{4}$ analyser (MA-10, Methane Analyzer, Sable Systems, Las Vegas, NV, USA). Data were adjusted for air flow rates, humidity and barometric pressure, which were constantly recorded during respirometry. Gas analysers were manually calibrated using commercially available calibration gases (pure nitrogen and a mixture containing $19.91 \% \mathrm{O}_{2}, 0.5032 \% \mathrm{CO}_{2}$, and $0.4945 \% \mathrm{CH}_{4}$ dissolved in nitrogen). Data obtained were analysed with the software ExpeData (Sable Sytems, Las Vegas, NV, USA) for $\mathrm{O}_{2}$ consumed and $\mathrm{CO}_{2}$ as well as $\mathrm{CH}_{4}$ emitted. Adjustments were made for gas concentrations in ingoing air. The mean metabolic rate (MR) was calculated based on the entire 23-h measurement period, while the resting MR (RMR) of the animals was calculated by averaging the 20 lowest $\mathrm{O}_{2}$ measurements per individual within the entire measurement. In order to estimate MR we multiplied the amount of $\mathrm{O}_{2}$ consumed (in $\mathrm{l} / \mathrm{h}$ ) by $20.08 \mathrm{~kJ} / 1 . \mathrm{CH}_{4}$ production was expressed in absolute values and in relation to intakes of DM, GE, digestible energy and digestible NDF, and was compared to the regression lines of $\mathrm{BM}$ vs $\mathrm{CH}_{4}$ production for ruminants and non-ruminants taken from Franz et al. (2011), and to $\mathrm{CH}_{4}$ results obtained from viscachas (Hagen et al., 2015a) and nutrias (Hagen et al., 2019). Volume measurements of $\mathrm{CH}_{4}$ were transformed to $\mathrm{CH}_{4}$ energy amounts using the conversion factor $39.57 \mathrm{~kJ} / 1$.

Statistical analyses were restricted to paired t-tests of MRT measurements of different markers performed with SPSS 22.0 (IBM, Armonk, NY, USA), with the significance level set to $P<0.05$ and with manual adjustment for multiple testing according to Sidak.

\section{Results}

Generally, the animals evaded the investigating person, moving to the opposite part of the enclosure or into the shelter, but did not seem stressed. They tolerated the period of $23 \mathrm{~h}$ confinement in the box without evident agitation, but gnawed on the metal sheets covering the air in- and outlets for varying periods of time.

On average, the animals ingested $59 \pm 9$ and $74 \pm 11$ g DM per kg metabolic BM $\left(\mathrm{BM}^{0.75}\right.$ and $\mathrm{BM}^{0.67}$, respectively) and day, and digested $49 \pm 3 \%$ of the organic matter and $35 \pm 4 \%$ of the NDF ingested (Table 2). The porcupines appeared to digest the diets with an efficiency in the lower range of what would be expected for horses at this crude fibre level (Figure 2).

The porcupines differed in the frequency of defecation; not all animals produced faeces in all collection periods. Two of the three faecal marker excretion patterns showed slight secondary marker peaks (Figure 3). The MRT of fluids (Co) and $2 \mathrm{~mm}$ $(\mathrm{Cr}), 10 \mathrm{~mm}(\mathrm{Ce})$ and $20 \mathrm{~mm}(\mathrm{La})$ particle markers were $26.4 \pm 1.4 \mathrm{~h}, 31.5 \pm 2.2 \mathrm{~h}, 26.8 \pm 2.5 \mathrm{~h}$ and $26.2 \pm 2.1 \mathrm{~h}$, respectively. In paired t-tests, $\mathrm{MRT}_{\mathrm{Cr}}$ was longer $(P<0.037)$ than MRT of the other markers within individuals, with no other significant differences. However, when correcting for multiple testing (post hoc Sidak adjustement), there were

Table 2. Body mass, intake and variables describing digestion of three individual Indian crested porcupine (Hystrix indica) fed lucerne pellets

\begin{tabular}{|c|c|c|c|}
\hline \multirow{2}{*}{ Indices } & \multicolumn{3}{|l|}{ Animal } \\
\hline & 1 & 2 & 3 \\
\hline Body mass, kg & 13.1 & 17.1 & 18.1 \\
\hline \multicolumn{4}{|l|}{ Dry matter (DM) intake } \\
\hline g/day & 476 & 429 & 463 \\
\hline $\mathrm{g} / \mathrm{kg}$ body mass $\mathrm{s}^{0.67} / \mathrm{day}$ & 85 & 64 & 67 \\
\hline $\mathrm{g} / \mathrm{kg}$ body mass $\mathrm{s}^{0.75} / \mathrm{day}$ & 69 & 51 & 53 \\
\hline Faecal DM excretion, g/day & 231 & 226 & 257 \\
\hline \multicolumn{4}{|l|}{ Apparent digestibility, \% } \\
\hline DM & 51.4 & 47.4 & 44.6 \\
\hline organic matter & 51.8 & 48.1 & 45.9 \\
\hline neutral detergent fibre & 40.1 & 32.7 & 32.4 \\
\hline gross energy & 49.8 & 45.7 & 42.1 \\
\hline $\begin{array}{l}\text { Digestible energy intake, } \mathrm{kJ} / \mathrm{kg} \\
\text { body mass }{ }^{0.75} / \text { day }\end{array}$ & 620 & 420 & 400 \\
\hline \multicolumn{4}{|l|}{ Mean retention time, $\mathrm{h}$} \\
\hline solutes & 26.7 & 24.8 & 27.7 \\
\hline particles $\mathrm{Cr}(2 \mathrm{~mm})^{1}$ & 29.8 & 30.7 & 34.0 \\
\hline particles $\mathrm{Ce}(10 \mathrm{~mm})^{1}$ & 26.3 & 24.6 & 29.4 \\
\hline particles La $(20 \mathrm{~mm})^{1}$ & 25.8 & 24.4 & 28.4 \\
\hline Calculated DM gut fill, g & 439 & 419 & 511 \\
\hline$\%$ of body mass & 3.36 & 2.46 & 2.82 \\
\hline
\end{tabular}

${ }^{1}$ note that the markers were chewed during ingestion and particle dimensions refer to the marker as offered, not as processed in the gastrointestinal tract 


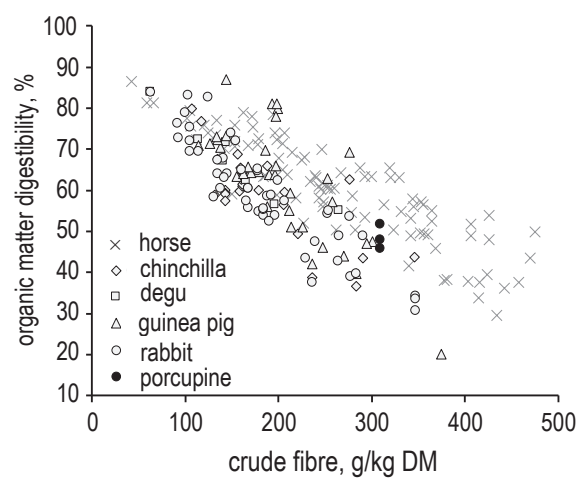

Figure 2. Relationship of dietary crude fibre levels (in g/kg dry matter) and measured apparent digestibility of organic matter (in \%) in horses, rabbits and rodents on various diets including pelleted feeds, forages, and mixed diets (data collection from Hagen et al. (2015b)) compared to the digestibility measured on pelleted lucerne in three Indian crested porcupine (Hystrix indica) of the present study (black circles)
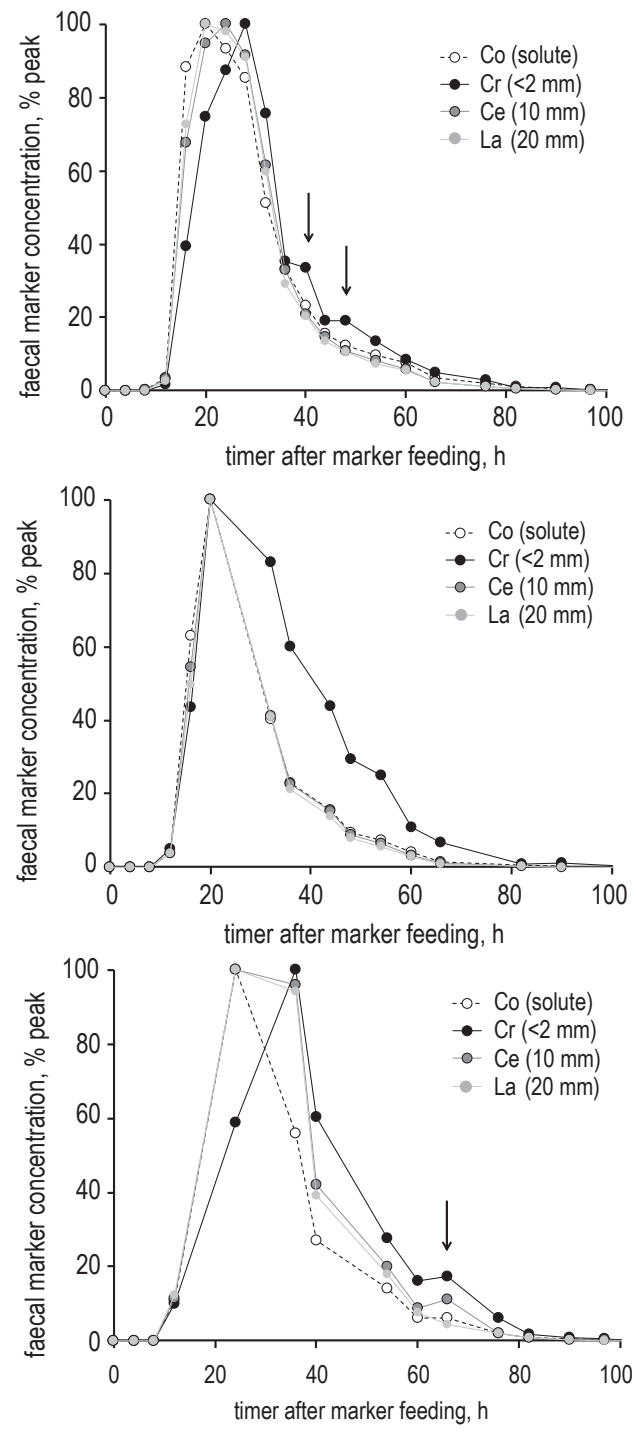

Figure 3. Excretion patterns for a solute (Co-EDTA) and three particle (Cr-mordanted fibre, <2 mm; Ce-mordanted fibre, $10 \mathrm{~mm}$; La-mordanted fibre, $20 \mathrm{~mm}$ ) marker in three Indian crested porcupine (Hystrix indica)

Arrows indicate secondary marker peaks potentially suggestive for caecotrophy no significant differences in any of these variables. The resulting ratios of $\mathrm{MRT}_{\mathrm{Co}} / \mathrm{MRT}_{\mathrm{Cr}}$ and $\mathrm{MRT}_{\mathrm{Co}} /$ $\mathrm{MRT}_{\mathrm{Ce}}$ were $0.84 \pm 0.05$ and $0.99 \pm 0.04$, respectively.

During respirometry, the animals showed a pattern of resting from the morning till the early afternoon, followed by intermittent bouts of activity (Figure 4). The respiratory quotient $\left(\mathrm{CO}_{2} / \mathrm{O}_{2}\right)$ was $0.91 \pm 0.03$ (Table 3), the average metabolic rate was $396 \pm 32 \mathrm{~kJ} / \mathrm{kg} \mathrm{BM}^{0.75} /$ day and the resting metabolic rate was $274 \pm 54 \mathrm{~kJ} / \mathrm{kg} \mathrm{BM}^{0.75} /$ day (Table 3 ). The animals had a relatively constant emission of $\mathrm{CH}_{4}$ over the day (Figure 4), which averaged at $8.16 \pm 0.211$ per day and $17.9 \pm 0.71$ per $\mathrm{kg} \mathrm{DMI}$ at a $\mathrm{CH}_{4}: \mathrm{CO}_{2}$ ratio of $0.058 \pm 0.006$ (Table 3 ). Methane yield ( $1 /$ $\mathrm{kg}$ DMI) was generally of a magnitude expected for a hypothetical ruminant of this BM (Figure 5).

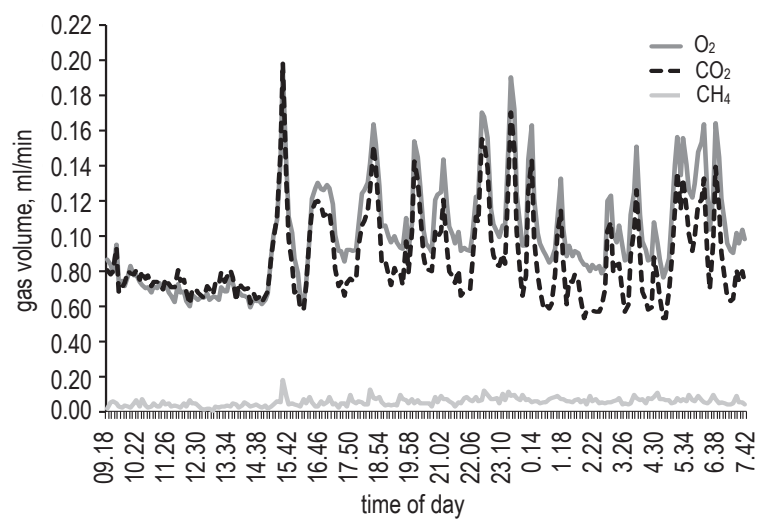

Figure 4. Representative pattern of respiration measurement results over time in one Indian crested porcupine (Hystrix indica) investigated in the present study

Table 3. Gaseous exchange of three individual Indian crested porcupine (Hystrix indica) fed pelleted lucerne

\begin{tabular}{|c|c|c|c|}
\hline \multirow{2}{*}{ Indices } & \multicolumn{3}{|l|}{ Animal } \\
\hline & 1 & 2 & 3 \\
\hline $\mathrm{O}_{2}$ consumption, I/day & 147 & 153 & 172 \\
\hline MR, $\mathrm{kJ} / \mathrm{kg}$ body mass ${ }^{0.75} /$ day & 429 & 365 & 394 \\
\hline Resting MR, kJ/kg body mass $s^{0.75} /$ day & 267 & 331 & 225 \\
\hline $\mathrm{CO}_{2}$ production, I/day & 126 & 141 & 160 \\
\hline $\mathrm{RQ}\left(\mathrm{CO}_{2} / \mathrm{O}_{2}\right)$ & 0.87 & 0.93 & 0.93 \\
\hline \multicolumn{4}{|l|}{$\mathrm{CH}_{4}$ production } \\
\hline I/day & 8.15 & 7.96 & 8.37 \\
\hline I/kg body mass/day & 0.62 & 0.47 & 0.46 \\
\hline I/kg dry matter intake & 31.9 & 43.0 & 30.4 \\
\hline$\%$ of gross energy intake & 3.78 & 4.09 & 3.98 \\
\hline$\%$ of digestible energy intake & 7.57 & 8.95 & 9.45 \\
\hline I/g dNDFI & 0.09 & 0.12 & 0.11 \\
\hline $\mathrm{CH}_{1}: \mathrm{CO}_{2}$ ratio & 0.065 & 0.057 & 0.052 \\
\hline
\end{tabular}

$\mathrm{MR}$ - metabolic rate; $\mathrm{RQ}$ - respiratory quotient; $\mathrm{dNDFI}$ - digestible neutral detergent fibre intake 

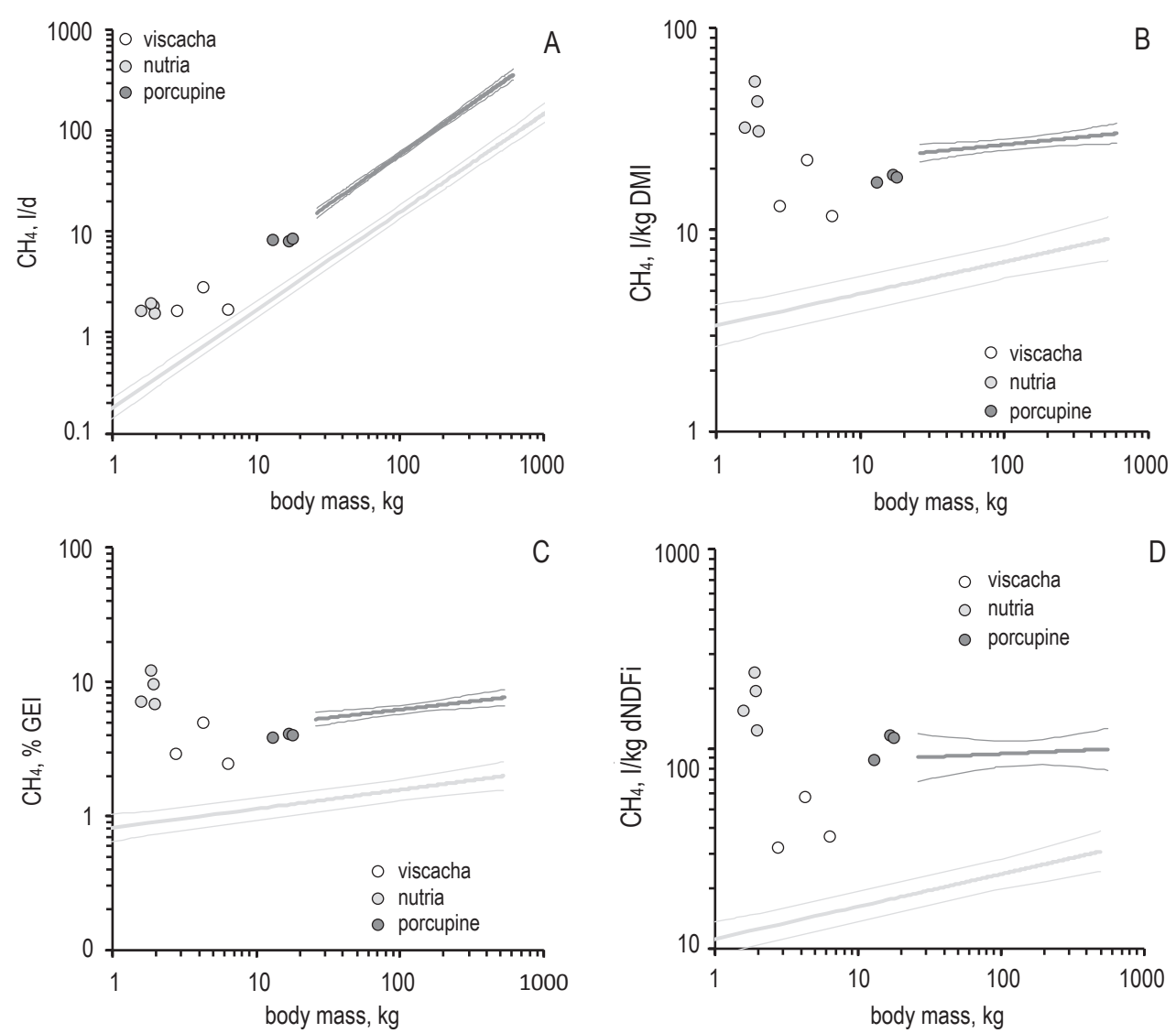

Figure 5. $\mathrm{CH}_{4}$ production of the three Indian crested porcupine (Hystrix indica) of the present study, three plains viscachas (Lagostomus maximus) from Hagen et al. (2015a), and four nutrias (Myocastor coypus) from Hagen et al. (2019) related to body mass as (A) absolute amount, (B) per unit of dry matter intake (DMI), (C) as a proportion of gross energy intake (GEI), and (D) per unit of digestible fibre intake (dNDFi), in comparison to ruminants (dark regression line) and non-ruminant mammalian herbivores (light regression line, Franz et al. (2011))

Table 4. Measurements of metabolism (basal metabolic rate (BMR), resting metabolic rate (RMR) or maintenance energy requirements) in porcupines from the literature and the present study

\begin{tabular}{|c|c|c|c|c|c|c|}
\hline \multirow{2}{*}{ Method/Species } & \multirow{2}{*}{$\begin{array}{l}\text { Body mass, } \\
\mathrm{kg}\end{array}$} & \multirow{2}{*}{$\begin{array}{l}\text { BMR } \\
\mathrm{kJ} \text { ME/kg } / .75 / \text { day }\end{array}$} & \multirow[t]{2}{*}{ RMR } & \multicolumn{2}{|l|}{ Maintenance $^{1}$} & \multirow{2}{*}{ Source } \\
\hline & & & & $\mathrm{kJ} \mathrm{DE} / \mathrm{kg}^{0.75} /$ day & $\mathrm{kJ} \mathrm{ME} / \mathrm{kg}^{0.75} /$ day & \\
\hline \multicolumn{7}{|l|}{ Respirometry } \\
\hline Coendou prehensilis & 3.3 & 182 & & & & McNab, 1978 \\
\hline Erethizon dorsatum & 11.1 & 220 & & & & Arends and McNab, 2001 \\
\hline \multirow{3}{*}{ Hystrix africaeaustralis } & 11.1 & & 184 & & & Haim et al., 1990b \\
\hline & 11.4 & & 260 & & & Haim et al., 1990a \\
\hline & 10.7 & & 166 & & & Haim et al., 1990a \\
\hline \multirow[t]{2}{*}{ Hystrix indica } & 12.8 & & 284 & & & Sever, 1986/1987 \\
\hline & $13-18$ & & 274 & & & this study \\
\hline \multicolumn{7}{|c|}{ Digestion study at body mass maintenance } \\
\hline Erethizon dorsatum ${ }^{2}$ & $10-12$ & & & $12-207$ & - & Felicetti et al., 2000 \\
\hline Hystrix indica ${ }^{3}$ & $15-17$ & & & 445 & 414 & Alkon et al., 1986 \\
\hline Hystrix indica ${ }^{4}$ & $13-18$ & & & 480 & 446 & this study \\
\hline
\end{tabular}

${ }^{1}$ metabolizable energy (ME) was estimated as $93 \%$ of digestible energy; time between body mass recording to assess body mass change:

25 days, ${ }^{3} 10$ days, ${ }^{4} 20$ days

\section{Discussion}

The present study supports previous findings that herbivorous rodents can achieve digestive efficiencies of a magnitude similar to that of horses and that substantial $\mathrm{CH}_{4}$ production is part of the digestive process (Hagen et al., 2015a; 2019). It supports, but does not conclusively prove, that caecotrophy is a typical component of the digestive strategy of porcupines. 
The major limitation of the present study was the low availability of specimens, limiting the sample size to three animals. All results therefore have to be considered as preliminary.

The present study was limited to a single experimental diet of high fibre (NDF $49 \%$ of DM) as well as high protein content (16\% of DM). The high NDF digestibilities reported for Hystrix africaeaustralis at 66 and 53\% for diets of lower and higher fibre levels (NDF 20 and $66 \%$ of DM, respectively) (van Jaarsveld, 1983), or for Erethizon dorsatum at $46-75 \%$ for various natural forages (NDF 32-60\% of DM) (Felicetti et al., 2000), were not achieved in the present study where the values ranged between 32 and $40 \%$. Therefore, the Hystrix indica used in the present study do not appear to be exceptional as compared to other herbivores, in contrast to the Erethizon dorsatum studied by Felicetti et al. (2000). This finding is also reflected in the general comparison with other hindgutfermenting mammals; for the crude fibre content of the diet used in the present study, Hystrix indica achieved an overall organic matter digestibility in the lower range of horses, and in the upper range of rabbits and guinea pigs (Figure 2).

Given that the range of digesta passage times previously reported for porcupines was large at 23-96 h (van Jaarsveld, 1983; Riccardi and Bruno, 1996; Felicetti et al., 2000), it is no surprise that the values determined in the present study fall within this range. At 24-30 h, the retention times measured in our porcupines were of a magnitude observed in horses at similar relative feed intake levels (Clauss et al., 2014). A limitation for the digestive efficiency of Hystricidae, compared to other hystricomorph rodents such as viscacha, might be the comparatively low chewing efficiency measured in this group in zoo animals via faecal particle size (Fritz et al., 2009). These results, however, should be confirmed by analysis of faecal material from free-ranging animals.

Porcupines are mainly nocturnal and in the wild, caecotrophy most likely occurs when the animals are resting. For burrowing or denning as well as for arboreal species, the behaviour may therefore be very elusive in the wild. Many porcupine species will switch readily to diurnal activity in captivity, which would shift the timing of resting and caecotrophy to the night time, where the animals will mostly be unobserved by personnel. Therefore, the lack of descriptions of caecotrophy in porcupines might stem from a lack of systematic observation during their period of inactivity. The marker excretion curves in two of the three animals of the present study contained secondary peaks, which have been considered to be indicators for caecotrophy (Clauss et al., 2007). It must be noted that theoretically, such peaks could also simply indicate a periodic release of caecum contents without caecotrophy as, for example, observed in birds (Frei et al., 2017). Ideally, therefore, passage studies in caecotroph species should simultaneously document behaviour by video surveillance, which was beyond the means of our current study. Thus, the evidence in published graphs (Felicetti et al., 2000) and the slight indication of the current experiment leaves caecotrophy a plausible yet not definitely proven part of porcupine digestive physiology. The intensity of caecotrophy varies depending on the diet fed (Hagen et al., 2015a), and the expression of secondary marker peaks will depend on the resolution of the marker excretion pattern, which in turn depends on the number of individual defecations. For example, the E. dorsatum studied by Felicetti et al. (2000) had a higher defecation frequency, and more prominent secondary marker peaks, than the animals in the present study (Figure 3), even though the latter did not appear stressed by the experiment and received a high-fibre diet. Whether a comparatively low defecation frequency is typical for $H$. indica would have to be assessed by future observations. For the future, we suggest that (infrared) video surveillance should be used to test whether captive porcupines indeed perform caecotrophy during their resting phase.

The solute and the two particle passage markers that were offered as larger particles moved in parallel through the digestive tract, whereas the marker offered as smaller particles was retained for a longer period of time, and was also the one that indicated the secondary peaks (Figure 3 ). We can only speculate that due to the comparatively low chewing efficiency of Hystricidae mentioned above, differences in the particle size of the markers remained in the gastrointestinal tract, and that the $\mathrm{Cr}$ marker actually represented a finer particle fraction that was most susceptible to differential retention by the colonic separation mechanism. Pei et al. (2001) suggested that $\mathrm{MRT}_{\text {solute }}: \mathrm{MRT}_{\text {particle }}$ ratios of up to 1.2 are typical for a 'mucus-trap' colonic separation mechanism that is linked to a colonic 'groove' or 'furrow' (Figure 1B). The values measured in the $H$. indica in the present study $(0.8-0.9$ for $\mathrm{Cr}$ particles and 0.9-1.0 for Ce particles) match this pattern, whereas the $E$. dorsatum studied by Felicetti et al. (2000) had ratios of 1.3-1.6, albeit measured with a different set of markers, which are above this range. 
The energy requirements of porcupines have been measured in different studies (Table 4). Notably, there was a close match between the respiration measurements of Sever (1986/1987) and the present study. The estimated requirements of digestible energy requirements for maintenance between Alkon et al. (1986) and the present study were also of a comparable magnitude; the corresponding estimations from Felicetti et al. (2000) appear unrealistically low, possibly because body mass changes were assessed over too short a period of time. The observation that our $H$. indica maintained body mass at their level of digestible energy intake over three weeks, as well as the measured resting metabolic rates, match these previous observations insofar as they indicate that porcupines, in general, have lower metabolic requirements than many other mammals. This has already previously been stated by $\mathrm{McNab}$ (1978) for Coendou prehensilis and by Haim et al. (1990b) for H. africaeaustralis, and conforms with the interpretation of Lovegrove (2001) that mammals that evolved body armour (such as quills) also evolved comparatively low rates of metabolism.

The respiration measurements also indicated relevant amounts of $\mathrm{CH}_{4}$ in our porcupines, at levels that are comparable to both absolute emissions and $\mathrm{CH}_{4}$ yield (per dry matter, gross energy or digestible fibre intake) to measurements in ruminants on forageonly diets (Figure 5). In addition to similar findings in viscachas and nutrias (Hagen et al., 2015a; 2019), they support the concept that a clear dichotomy in terms of $\mathrm{CH}_{4}$ emissions between ruminant and non-ruminant mammals, as previously proposed (Franz et al., 2011), is unlikely to be correct, and that the involvement of methanogens in processes of fibre digestion are more ubiquitous across herbivorous mammals than previously thought.

\section{Conclusions}

Our findings characterise Indian crested porcupines as animals with digestive efficiencies and digesta retention times similar to other large rodents and the hindgut fermenter horse, and which produce $\mathrm{CH}_{4}$ during fibre digestion. The obtained results suggest that caecotrophy could occur in porcupines. Porcupines appear to have maintenance requirements that are slightly below the mammalian average. Indirectly, the results of the study also suggest that there is no need to feed these animals with the energy dense diets consisting of bread, grains and fruits, which are often given to porcupines in captivity, because they are able to maintain body mass on fibrous diets.

\section{Acknowledgements}

We thank Catrin Hammer for her support of our study, and Heidrun Barleben and Carmen Kunz for chemical analyses. This study was part of project 310030_135252/1 funded by the Swiss National Science Foundation.

\section{References}

Alkon P.U., Degen A.A., Cohen A., Pollak H., 1986. Seasonal energy requirements and water intakes of Indian crested porcupines (Hystrix indica) in captivity. J. Mammal. 67, 333-342, https:// doi.org/10.2307/1380887

AOAC International, 2016. Official Methods of Analysis of the AOAC International. $20^{\text {th }}$ Edition Gaithersburg, MD (USA)

Arends A., McNab B.K., 2001. The comparative energetics of 'caviomorph' rodents. Comp. Biochem. Physiol. A 130, 105-122, https://doi.org/10.1016/S1095-6433(01)00371-3

Björnhag G., 1987. Comparative aspects of digestion in the hindgut of mammals. The colonic separation mechanism (CSM) (a review). Dtsch. Tierärztl. Wochenschr. 94, 33-36

Clauss M., Besselmann D., Schwarm A., Ortmann S., Hatt J.-M., 2007. Demonstrating coprophagy with passage markers? The example of the plains viscacha (Lagostomus maximus). Comp. Biochem. Physiol. Part A. Mol. Integr. Physiol. 147, 453-459, https://doi.org/10.1016/j.cbpa.2007.01.013

Clauss M., Schiele K., Ortmann S., Fritz J., Codron D., Hummel J., Kienzle E., 2014. The effect of very low food intake on digestive physiology and forage digestibility in horses. J. Anim. Physiol. Anim. Nutr. 98, 107-118, https://doi.org/10.1111/jpn.12053

Felicetti L.A., Shipley L.A., Witmer G.W., Robbins C.T., 2000. Digestibility, nitrogen excretion, and mean retention time by North American porcupines (Erethizon dorsatum) consuming natural forages. Physiol. Biochem. Zool. 73, 772-780, https:// doi.org/10.1086/318094

Franz R., Soliva C.R., Kreuzer M., Hummel J., Clauss M., 2011. Methane output of rabbits (Oryctolagus cuniculus) and guinea pigs (Cavia porcellus) fed a hay-only diet: Implications for the scaling of methane production with body mass in nonruminant mammalian herbivores. Comp. Biochem. Physiol. Part A. Mol. Integr. Physiol. 158, 177-181, https://doi. org/10.1016/j.cbpa.2010.10.019

Frei S., Ortmann S., Kreuzer M., Hatt J.-M., Clauss M., 2017. Digesta retention patterns in geese (Anser anser) and turkeys (Meleagris gallopavo) and deduced function of avian caeca. Comp. Biochem. Physiol. Part A. Mol. Integr. Physiol. 204, 219-227, https://doi.org/10.1016/j.cbpa.2016.12.001

Fritz J., Hummel J., Kienzle E., Arnold C., Nunn C., Clauss M., 2009. Comparative chewing efficiency in mammalian herbivores. Oikos 118, 1623-1632, https://doi.org/10.1111/j.16000706.2009.17807.x

Gorgas M., 1967. Comparative anatomical studies on the gastrointestinal tract of Sciuromorpha, Hystricomorpha and Caviomorpha (Rodentia) (in German: Vergleichend-anatomische Untersuchungen am Magen-Darm-Kanal der Sciuromorpha, Hystricomorpha und Caviomorpha (Rodentia)). Z. Wiss. Zool. 175, 237-404

Hackstein J.H.P., van Alen T.A., 1996. Fecal methanogens and vertebrate evolution. Evolution; Int. J. Org. Evol. 50, 559-572, https://doi.org/10.1111/j.1558-5646.1996.tb03868.x 
Hagen K.B., Besselmann D., Cyrus-Eulenberger U., Vendl C., Ortmann S., Zingg R., Kienzle E., Kreuzer M., Hatt J.-M., Clauss M., 2015a. Digestive physiology of the plains viscacha (Lagostomus maximus), a large herbivorous hystricomorph rodent. Zoo Biol. 34, 345-359, https://doi.org/10.1002/ zoo.21216

Hagen K.B., Frei S., Ortmann S., Głogowski R., Kreuzer M., Clauss M., 2019. Digestive physiology, resting metabolism and methane production of captive juvenile nutria (Myocastor coypus). Eur. J. Wildl. Res. 65, 2, https://doi.org/10.1007/s10344-0181239-1

Hagen K.B., Tschudin A., Liesegang A., Hatt J.-M., Clauss M., 2015b. Organic matter and macromineral digestibility in domestic rabbits (Oryctolagus cuniculus) as compared to other hindgut fermenters. J. Anim. Physiol. Anim. Nutr. 99, 1197-1209, https://doi.org/10.1111/jpn.12323

Haim A., Van Aarde R.J., Skinner J.D., 1990a. Metabolic rates, food consumption and thermoregulation in seasonal acclimatization of the Cape porcupine (Hystrix africaeaustralis). Oecologia 83, 197-200, https://doi.org/10.1007/BF00317752

Haim A., Van Aarde R.J., Skinner J.D., 1990b. Metabolism and thermoregulation in the cape porcupine, Hystrix africaeaustralis. Physiol. Zool. 63, 795-802, https://doi.org/10.2307/30158177

Hirakawa H., 2001. Coprophagy in leporids and other mammalian herbivores. Mammal Rev. 31, 61-80, https://doi.org/10.1046/ j.1365-2907.2001.00079.x

Holleman D.F., White R.G., 1989. Determination of digesta fill and passage rate from non absorbed particulate phase markers using the single dosing method. Can. J. Zool. 67, 488-494, https://doi.org/10.1139/z89-071

Johnson J.L., McBee R.H., 1967. The porcupine cecal fermentation. J. Nutr. 91, 540-546, https://doi.org/10.1093/jn/91.4.540

Lovegrove B.G., 2001. The evolution of body armor in mammals: plantigrade constraints of large body size. Evolution 55, 14641473, https://doi.org/10.1111/j.0014-3820.2001.tb00666.x

McNab B.K., 1978. Energetics of arboreal folivores: physiological problems and ecological consequences of feeding on an ubiquitous food supply. In: G.G. Montgomery (Editor). The Ecology of Arboreal Folivores. Smithsonian Institution Press. Washington DC (USA), pp. 153-162
Mori E., Bozzi R., Laurenzi A., 2017. Feeding habits of the crested porcupine Hystrix cristata L. 1758 (Mammalia, Rodentia) in a Mediterranean area of Central Italy. Eur. Zool. J. 84, 261-265, https://doi.org/10.1080/24750263.2017.1329358

Pei Y.-X., Wang D.-H., Hume I.D., 2001. Selective digesta retention and coprophagy in Brandt's vole (Microtus brandti). J. Comp. Physiol. B 171, 457-464, https://doi.org/10.1007/ s003600100195

Riccardi C., Bruno E., 1996. Food intake of captive porcupines Hystric cristata (Rodentia, Hystricidae). Atti Soc. Tosc. Sci. Nat., Mem. B. 103, 81-83

Schwarm A., Ortmann S., Wolf C., Clauss M., 2009. No distinct difference in the excretion of large particles of varying size in a wild ruminant, the banteng (Bos javanicus). Eur. J. Wildl. Res. 55, 531-533, https://doi.org/10.1007/s10344-009-0277-0

Sever Z., 1986/1987. Water and energy economies of captive porcupines and their implications under natural conditions. Israel J. Zool. 34, 97-98

Thielemans M.-F., François E., Bodart C., Thewis A., 1978. Gastrointestinal transit in the pig:measurement using radioactive lanthanides and comparison with sheep (in French: Mesure du transit gastrointestinal chez le porc a l'aide des radiolanthanides. Comparaison avec le mouton.) Ann. Biol. Anim. Biochim. Biophys. 18, 237-247, https://hal.archives-ouvertes.fr/ hal-00897286

van Jaarsveld A.S., 1983. Aspects of the digestion in the Cape porcupine. S. Afr. J. Anim. Sci. 13, 31-33

van Jaarsveld A.S., Knight-Eloff A.K., 1984. Digestion in the porcupine Hystrix africaeaustralis. S. Afr. J. Zool. 19, 109-112, https:// doi.org/10.1080/02541858.1984.11447867

Vispo C., Hume I.D., 1995. The digestive tract and digestive function in the North American porcupine and beaver. Can. J. Zool. 73, 967-974, https://doi.org/10.1139/z95-113 